\title{
Comparações florísticas e taxonomia da família Gesneriaceae no Parque Nacional do Itatiaia, Brasil
}

\author{
Maria Jullyana G. de Barros ${ }^{1}$, Vidal de Freitas Mansano ${ }^{1,3}$ e Alain Chautems ${ }^{2}$
}

Recebido: 11.08.2008; aceito: 26.03.2010

\begin{abstract}
Floristic comparisons and taxonomy of the family Gesneriaceae from Itatiaia National Park, Brazil). The family Gesneriaceae is composed by about 140 genera and 3,500 species. In Brazil there are about 22 genera and 220 species. The Itatiaia National Park is an area with a great altitudinal variation, and, for consequence with a high diversity of vegetal formations, from moist forests to "campos". This paper is based on a bibliographic revision, analysis of herbarium material, field observations and collections. Floristic comparisons were made using the Jaccard similarity index to verify the similarities among the Gesneriaceae of the Itatiaia National Park and surrounded areas of the states of Rio de Janeiro and Minas Gerais. Three genera and nine species were identified: Besleria (1 sp.), Nematanthus (3 spp.) and Sinningia (5 spp.). Identification keys to the genera and species, descriptions, illustrations and taxonomic comments are presented. The flora of Gesneriaceae of Itatiaia is more similar to areas such as Serra do Brigadeiro and Serra do Caparaó in Minas Gerais than of the tested areas of the state of Rio de Janeiro.
\end{abstract}

Key words: Besleria, floristic similarity, Nematanthus, Sinningia, taxonomy

RESUMO - (Comparações florísticas e taxonomia da família Gesneriaceae no Parque Nacional do Itatiaia, Brasil). A família Gesneriaceae é composta por cerca de 140 gêneros e 3.500 espécies. No Brasil existem cerca de 22 gêneros e 220 espécies. O Parque Nacional do Itatiaia possuiu grande variação altitudinal, e por conseqüência grande diversidade de formações vegetais, tendo desde floresta úmida até campos. Este trabalho baseia-se no levantamento bibliográfico, consulta a herbários, coletas e observações de campo. Também foram feitas comparações florísticas utilizando o índice de similaridade de Jaccard para verificar similaridades entre as Gesneriaceae do Itatiaia e de áreas próximas do Rio de Janeiro e Minas Gerais. Foram registrados três gêneros e nove espécies: Besleria (1 sp.), Nematanthus (3 spp.) e Sinningia (5 spp.). São apresentadas chaves de identificações para gêneros e espécies, descrições, ilustrações e comentários taxonômicos. A flora de Gesneriaceae do Itatiaia é mais semelhante a áreas como a Serra do Brigadeiro e a Serra do Caparaó em Minas Gerais do que com as áreas testadas no estado do Rio de Janeiro.

Palavras-chave: Besleria, Nematanthus, similaridade florística, Sinningia, taxonomia

\section{Introdução}

A família Gesneriaceae Rich. \& Juss. ex DC. é composta por cerca de 140 gêneros e 3.500 espécies (Weber 2004), sendo que no Brasil ocorrem cerca de 22 gêneros e 220 espécies (Chautems \& Kiyama 2003, Araujo et al. 2005). As Gesneriaceae estão distribuídas nos trópicos e subtrópicos dos dois hemisférios, sendo pouco representadas na África e marginalmente na Europa (Barroso et al. 1984, Judd et al. 2002). Segundo Judd et al. (2002) e Souza \& Lorenzi (2005) esta família está inserida na ordem
Lamiales sendo proximamente relacionada às famílias Plumbaginaceae, Lentibulariaceae, Calceolariaceae e Oleaceae. Muitas espécies de Gesneriaceae são utilizadas como ornamentais, dentre eles merecem destaque às plantas do gênero Episcia Mart., a belíssima gloxínia do gênero Sinningia Nees e a conhecida violeta africana do gênero Saintpaulia $\mathrm{H}$. Wendl., além de alguns exemplares de Aeschynanthys Jack e Columnea L. (Judd et al. 2002).

Dusén (1903) incluiu somente três espécies de Gesneriaceae para o Parque Nacional do Itatiaia (PNI), com base nas coletas do Ule, mas ele comenta

1. Instituto de Pesquisas Jardim Botânico do Rio de Janeiro, Rua Pacheco Leão 915, 22460-030 Rio de Janeiro, RJ, Brasil

2. Conservatoire et Jardin Botaniques de la Ville de Genève, Caixa Postal 60, CH-1292 Chambésy, Genebra, Suíça

3. Autor para correspondência: vidal@jbrj.gov.br 
que provavelmente as coleções a disposição são lacunares. Mais tarde, Dusén (1909) cita mais quatro espécies com base em suas próprias coletas. Brade (1956) reconhece os seguintes gêneros como ocorrentes nesta área: Besleria L., Codonanthe (Mart.) Hanst., Corytholoma (Benth.) Decne. [= Sinningia Nees], Hyporcyta Mart. [= Nematanthus Schrad.] e Nematanthus Schrad. A estes gêneros o autor subordinou dez espécies. O trabalho mais recente sobre as Gesneriaceae de Itatiaia foi feito por Barroso (1957), onde a autora reconheceu também dez espécies subordinadas a cinco gêneros. Barroso (1957) cita Crantzia hirtella $[=$ Nematanthus hirtellus (Schott) Wiehler], que não havia sido citado por Brade (1956) e não citou Codonanthe.

O objetivo desse trabalho é apresentar as espécies de Gesneriaceae, identificando a ocorrência destas nas diferentes formações florestais do PNI. Desta forma são apresentadas descrições, chaves de identificação, ilustrações, comentários e comparações florísticas.

\section{Material e métodos}

O Parque Nacional do Itatiaia (PNI) está localizado na região Sudeste do Brasil, mais especificamente entre o sudoeste do estado do Rio de Janeiro e o sul do estado de Minas Gerais (22 30' 22 33' S e 42 15' - 42 19' W), abrangendo uma área de cerca de 30.000 hectares (figura 1). Está inserido no maciço do Itatiaia, um dos grandes afloramentos rochosos do mundo, constituído por rochas do tipo Nefelino e por massas de Sienito (Segadas-Vianna 1965). Dentre as bacias hidrográficas que se destacam na região estão as do rio Paraíba do Sul e do rio Paraná (MA-IBDF \& FBCN 1982, Brade 1956). O PNI é caracterizado por um relevo de elevações rochosas que variam de 650 a 2.780 m (Morim 2002).

Neste trabalho usamos o sistema de SegadasVianna (1965) para comentar a distribuição das espécies no Parque. O autor estabeleceu "andares de vegetação" abrangendo cinco faixas altimétricas: planície de 400 a 700 metros de altitude (aqui será tratada como base da montanha, visto que não há planície propriamente dita dentro do domínio do Parque); montanha inferior de 700 a 1.100 metros de altitude; montanha média 1.100 a 1.700 metros de altitude; montanha superior de 1.700 a 2.000 metros de altitude; planalto de 2.000 a 2.400 metros de altitude e cumes de 2.400 a 2.770 metros de altitude.

O levantamento das espécies de Gesneriaceae do PNI foi feito a partir do material depositado nos herbários GUA, HB, R, RB, S, SP e SPF (siglas de acordo com Holmgren et al. 1990). Foram também realizadas expedições para coleta e observação de populações naturais na área de estudo.

Comparações florísticas entre Itatiaia e floras de diferentes áreas de Minas Gerias como Cadeia do Espinhaço, Parque Nacional Serra do Caparaó e Parque Estadual Serra do Brigadeiro e do Rio de Janeiro como Reserva Ecológica de Macaé de Cima, Área de Proteção Ambiental de Cairuçu, Reserva Florestal Vista Chinesa e Reserva Rio das Pedras foram feitas através de matrizes de presença ou ausência ( 1 e 0 ). Tais matrizes foram analisadas quanto às espécies que ocorriam em determinadas regiões (similaridade florística).

Com o auxílio do aplicativo NTSYS 2.1 (Rohlf 2000), foi calculado para cada matriz o coeficiente de similaridade entre as unidades de amostradas (espécie $\mathrm{X}$ espécie) por meio do SIMQUAL (similaridade para dados qualitativos) utilizando o coeficiente de Jaccard $(\mathrm{J}=\mathrm{c} /(\mathrm{a}+\mathrm{b}+\mathrm{c}))$, onde c é o número de ocorrência em comum às unidades amostrais, a é o número de ocorrência restrito a unidade amostral $1, b$ é o número de ocorrência restrito à unidade amostral 2.

Com o coeficiente de similaridade de Jaccard foram gerados os dendrogramas pelo método hierárquico de agrupamento UPGMA (Unweighted Pair Group Main Average).

\section{Resultados e Discussão}

Gesneriaceae Rich \& Juss. ex DC., Essai Prop. Med. Pl. 2: 192. 1816.

Ervas, subarbustos ou raramente arbustos, terrestres, litofíticos ou epifíticos; caule herbáceo ou lenhoso, ereto, escandente ou pendente, às vezes com raízes adventícias ou tuberoso na base. Folhas simples, opostas, às vezes verticiladas, pecioladas, lâmina inteira, margem lisa, dentada ou serreada, às vezes revoluta membranácea, crassa ou subcoriácea, discolores. Inflorescência axilar (pediceladas ou quase sésseis) ou terminal (cimosas ou solitárias), brácteas caducas ou geralmente persistentes, raramente ausentes. Flores vistosas, zigomorfas, raramente actinomorfas, andróginas, protândricas, ressupinadas ou não, cálice foliáceo (verde ou colorido), pentâmero; sépalas unidas somente na base, inteiras a denteadas; corola tubulosa, algumas 


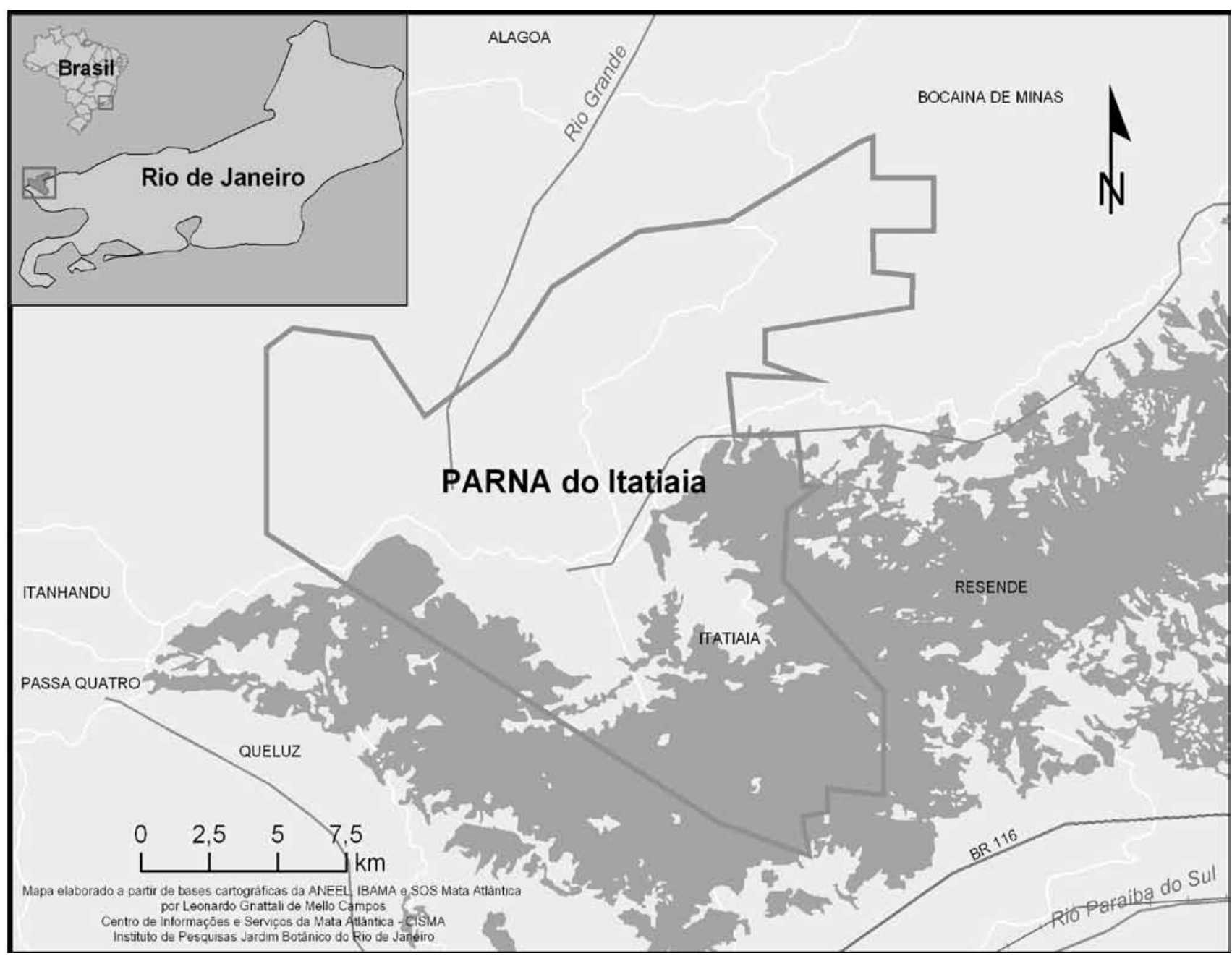

Figura 1. Mapa de localização do Parque Nacional do Itatiaia.

Figure 1. Map showing the "Parque Nacional do Itatiaia".

vezes gibosa ou arqueada na parte mediana, colorida, raramente branca, lobos iguais ou desiguais, eretos ou patentes; 4 estames inclusos, raramente exertos, epipétalos, anteras unidas, rimosas; nectário aderido à base do ovário ou livre, anular ou dividido em 2-5 glândulas, geralmente separadas, às vezes 2 juntas em posição dorsal; ovário súpero a semi-ínfero, 2-carpelar, 1-locular, placentação parietal, estilete simples. Fruto baga ou cápsula seca ou carnosa, sementes com funículo carnoso.

\section{Chave para a identificação dos gêneros ocorrentes no PNI}

1. Caule tuberoso na base; fruto seco (cápsula)

Sinningia

1. Caule nunca tuberoso na base; fruto carnoso

2. Arbustos terrestres; fruto baga globosa

Besleria

2. Subarbustos terrestres; epifíticos ou litofíticos; fruto cápsula carnosa Nematanthus

\section{Besleria L., Sp. Pl. 2: 619. 1753.}

Arbustos terrestres, caule mais ou menos lenhoso, nunca tuberoso na base, raízes terrestres, ramos cilíndricos a quadrangulares; sistema subterrâneo tuberoso ausente. Folhas opostas, membranáceas, pecíolo verde, margem inteira a levemente denteada. Inflorescência axilar, cimosa, sem brácteas; sépala verde; corola tubulosa com lobos subiguais, amarelas a brancas; anteras inclusas; nectário anular; ovário súpero, estigma incluso. Fruto baga globosa. 
No PNI é representado apenas por uma espécie.

Besleria umbrosa Mart., Nov. Gen. Sp. Pl. 3: 44, t. 218. 1829.

Figura 2A-E

Arbustos terrestres; ramos cilíndricos; glabrescentes. Folhas às vezes anisófilas; pecíolo ca. 1,3-3,5 cm, verde, pubescente, lâmina elíptica a oblongo-obovada, 14-18,5 5,3-7,6 cm, ápice cuspidado e base atenuada, face abaxial pubérula, tricomas mais concentrados ao longo das nervuras, margem e ápice e face adaxial glabra; margem inteira a levemente dentada. Inflorescência com 2-3 flores; pedúnculo ca. $3,5 \mathrm{~cm}$, pubérulo; pedicelo $2-1,7 \mathrm{~cm}$, pubérulo; sépalas ca. $97 \mathrm{~mm}$, ovado-lanceoladas, agudas no ápice, arredondadas na base, pubérulas, verde-esbranquiçada; corola 1,8-2,0 0,6 cm, tubulosa, amarela, lobos patentes, amarelos na face externa, esbranquiçados na face interna, face interna e externa glabra; filetes $1,0-1,5 \mathrm{~cm}$; ovário glabro a pubescente, estilete ca. $1 \mathrm{~cm}$, pubescente apenas no ápice. Fruto 1-1,5 1-1,4 cm.

Material selecionado: BRASIL. RIO DE JANEIRO: Itatiaia, Serra da Capelinha, VII-1937, fl., Luiz 80 (RB); Margem esquerda do córrego do Marimbondo, 15-X-1986, fl., Pineslhi 13 (GUA); Resende, Serra da Mantiqueira, Próximo à cachoeira do Alcantilado, 24-VI-1994, fl., Rossi s.n. (SP).

Material adicional: BRASIL. RIO DE JANEIRO: Petrópolis, meio da estrada de Petrópolis, VIII/1944, fl., Góes s.n. (RB 102309); Fazenda Inglesa, 25IX-1981, fl., Martinelli \& Leme 7712 (RB); Nova Iguaçu, Margem da estrada para a represa de Colomi, 6-X-1993, fr., Neto \& Silva 307 (RB).

Ocorre no Rio de Janeiro e em São Paulo na Serra da Mantiqueira (Chautems \& Kyiama 2003). Encontrada a cerca de $680 \mathrm{~m}$ alt. na área estudada. Esta altitude corresponde à planície, segundo Segadas-Vianna (1965), ou base da montanha como tratado aqui e é uma região dominada por mata úmida com árvores de grande porte (tabela 1). Coletada com flores de julho a outubro.

Nematanthus Schrad., Gott. Gel. Anz. 1: 718. 1821.

Subarbustos terrestres, epifíticos ou litofíticos, caule mais ou menos lenhoso, nunca tuberoso na base, ramos cilíndricos, raízes adventícias presentes. Folhas anisófilas ou não, opostas, crassas, pecíolo verde ou vinoso, margem inteira. Flores simples, axilares, pendentes ou eretas, ressupinadas ou não, brácteas muitas vezes caducas ou ausentes; sépalas verde-claras a vermelho-escuras; corola tubulosa, ventricosa a campanulada, gibosa amarela, vermelha ou ainda laranja com lobos amarelos; lobos eretos ou revolutos, anteras inclusas; ovário súpero, estigma incluso; nectário formado por uma glândula dorsal. Fruto cápsula carnosa, loculicida.

Chave para a identificação das espécies de Nematanthus ocorrentes no PNI

1. Flores pêndulas; pedicelo 5-6,5 cm compr.; corola 3,5-5,5 cm compr. N. crassifolius

1. Flores nunca pendentes; pedicelo $0,4-0,8 \mathrm{~cm}$ compr.; corola 2-3 cm compr.

2. Pecíolo até $1 \mathrm{~cm}$ compr., verde; cálice com sépalas ovadas .................................. N. fornix

2. Pecíolo 1,3-6,4 cm compr., vinoso; cálice com sépalas orbiculares N. lanceolatus

Nematanthus crassifolius (Schott) Wiehler, Selbyana 5(3-4): 382. 1981.

Figura 2F-I

Subarbustos epifíticos ou litofíticos, ramo cilíndrico, glabro. Folhas geralmente anisófilas, pecíolo ca. 1,2-2 cm, verde, glabro; lâmina ovadoelíptica, 5,1-12 1,8-10 cm, ápice acuminado e base atenuada, face abaxial e adaxial levemente glabrescente, margem glabrescente. Flores axilares solitárias, ressupinadas, pêndulas; pedicelo 5-6,5 $\mathrm{cm}$, pubescente na proximidade da flor brácteas ausentes; sépalas ca. 3,2 0,7 cm, foliáceas, acuminadas, ovadas, pubérulas, verde-amareladas, margens pubescentes; corola avermelhada 3,5-5,5 $2,5 \mathrm{~cm}$, tubular-infundibuliforme, lobos revolutos, concolores, glabrescente em ambas as faces; filetes ca. 3,6-4,6 cm, glabros, concrescidos entre si na base por até $1 / 3$ de comp; gineceu com ovário pubescente, estilete 3-4,5 cm, pubérulo. Fruto 2,5-3 1,5-2 cm.

Material selecionado: BRASIL. RIO DE JANEIRO: Itatiaia, mata em pedra, 7-VI-1902, fl., Dusen 534 (R); Parque Nacional do Itatiaia, Caminho para Itaporani, 8-IX-1988, fl., Giordano et al. 443 (RB); Caminho para cachoeira Véu da Noiva, 24-VI-2003, fl., Canela et al. 8 (RB); Último Adeus, 17-II-1948, fl., Brade 18862 (RB); Caminho entre Maromba e Macieras, 26-IV-1983, fl., Chautems et al. 102 (RB); 21-VIII-2004, fl., Barros et al. 1 (RB); trilha do Hotel Simon para os Três Picos, 5-X-1994, fl., Braga et al. 1368 (RB); Maromba, Trilha para Cachoeira Itaporani, 4-X-1994, fl., Braga et al. 1345 (RB); 
Trilha para Cachoeira Véu da Noiva, margem do rio Maromba, 14-IX-1994, fl., Lima et al. 314 (RB).

Ocorre nos estados de São Paulo, Rio de Janeiro, Minas Gerais e Espírito Santo, nas encostas da Serra do Mar, da Mantiqueira ou em torno do maciço do Caparaó. Na área estudada, foi encontrada entre 700 a $1.500 \mathrm{~m}$, em locais úmidos, preferencialmente. A faixa altitudinal desta espécie na área abrange o que Segadas-Vianna (1965) chamava de montanha inferior e montanha média, ambas as áreas são ocupadas por matas densas e com árvores de grande porte (tabela 1). Coletada com flores em fevereiro, abril, agosto, setembro e outubro.

Nematanthus fornix (Vell.) Chautems, Candollea 39(1): 298.1984.

Figura 2J-N

Subarbustos epifíticos ou às vezes litofíticos; ramos cilíndricos, glabro a pubérulo. Folhas por vezes anisófilas; pecíolo ca. 7-10 $\mathrm{mm}$, verde, pubérulo; lâmina ovado-elíptica, 3,5-6,3 × 1,5-2,5 cm, ápice agudo e base cuneada, face abaxial pubérula, face adaxial pubérula; margem ciliada. Flores 1-2 por axila; pedicelo ca. 6-8 $\mathrm{mm}$; brácteas presentes; sépalas ca. 1,5 ×0,8 cm, ovadas, agudas no ápice, unidas na base, verdes; corola 2,2-3 × 1,0 cm, giboventricosa, vermelho-vivo, lobos eretos e patentes, concolores, face interna e externa pubescente, tricomas glandulosos presentes; filetes $1,1-2,1 \mathrm{~cm}$, pubescentes; ovário pubescente, estilete ca. $1,5 \mathrm{~cm}$, pubescente. Fruto 1,3-1,6 × 1-1,3 cm.

Material selecionado: BRASIL. RIo DE JANEIRO: Parque Nacional do Itatiaia, Ponte Maromba, lado direito em direção à guarita, 10-IX-2003, fl., Canela et al. 19 (RB); estrada em direção à Agulhas Negras, 18-X-1977, fl., Landrum 2115 (RB); Resende, Serra de Itatiaia, Visconde de Mauá, Vale do Pavão, caminho para cachoeira do Marimbondo, 7-X-1979, fl., Martinelli 6180 (RB); trilha do Hotel Simon para o Três Picos, 5-X-1994, fl., Braga et al. 1383 (RB); Morrey-Jones et al. 12 (RB); Ponte do Maromba, próximo do estacionamento, margem do rio Campo Belo, 8-XI-1993, fl., Guedes et al. 2298 (RB); Mt. Itatiaya, IX-1901, fl., Wettstein et al. s.n. (WU).

Ocorre no Rio de Janeiro e em São Paulo, nas matas de altitude da Serra da Mantiqueira e da Serra do Mar, entre 1.200 e 1.800 m. (Chautems \& Kyiama 2003). Na área estudada ocorre a ca. 1.000 até pouco acima de $2.000 \mathrm{~m}$. Foi observado na mesma faixa na Bocaina, e na Serra dos Órgãos. Nota-se que se trata de um táxon com grande amplitude altitudinal abrangendo diferentes formações vegetais da área. Segundo Segadas-Vianna (1965) esta espécie abrange desde a montanha média com floresta densa, até os

Tabela 1. Relação dos táxons de Gesneriaceae ocorrentes no Parque Nacional do Itatiaia, correlacionando faixa altitudinal com seu andar de vegetação correspondente e ainda a formação vegetal presente na amplitude de ocorrência. *Segundo Segadas-Vianna (1965), com a adaptação para o termo planície aqui tratada por base da montanha.

Table 1. Gesneriaceae taxa occuring in the Parque Nacional do Itatiaia, correlating altitudinal range with its corresponding vegetation strip and vegetation type. *According to Segadas-Vianna (1965), except for prairie here replaced by base of the mountain.

\begin{tabular}{lllc}
\hline \multicolumn{1}{c}{ Táxon } & \multicolumn{1}{c}{ Faixa altitudinal } & Andar de vegetação* & $\begin{array}{c}\text { Formação } \\
\text { dominante }\end{array}$ \\
\hline Besleria umbrosa & ca. $680 \mathrm{~m}$ & base da montanha & mata \\
Nematanthus crassifolius & $700 \mathrm{a} 1.800 \mathrm{~m}$ & montanha inferior e média & mata \\
N. fornix & $1.100 \mathrm{a} \mathrm{um} \mathrm{pouco}$ & montanha inferior e planalto & mata e campos \\
N. lanceolatus & acima de $2.000 \mathrm{~m}$ & montanha inferior & mata \\
Sinningia allagophylla & 850 a $900 \mathrm{~m}$ & planalto & campos \\
S. gigantifolia & $<2.100 \mathrm{~m}$ & montanha inferior a planalto & mata e campos \\
S. magnifica & $850 \mathrm{a} 2.400 \mathrm{~m}$ & montanha inferior a planalto & mata e campos \\
S. sceptrum & $1.000 \mathrm{a} 2.100 \mathrm{~m}$ & montanha inferior & mata \\
S. aggregata & $800 \mathrm{a} 1.200 \mathrm{~m}$ & montanha inferior e média & mata
\end{tabular}




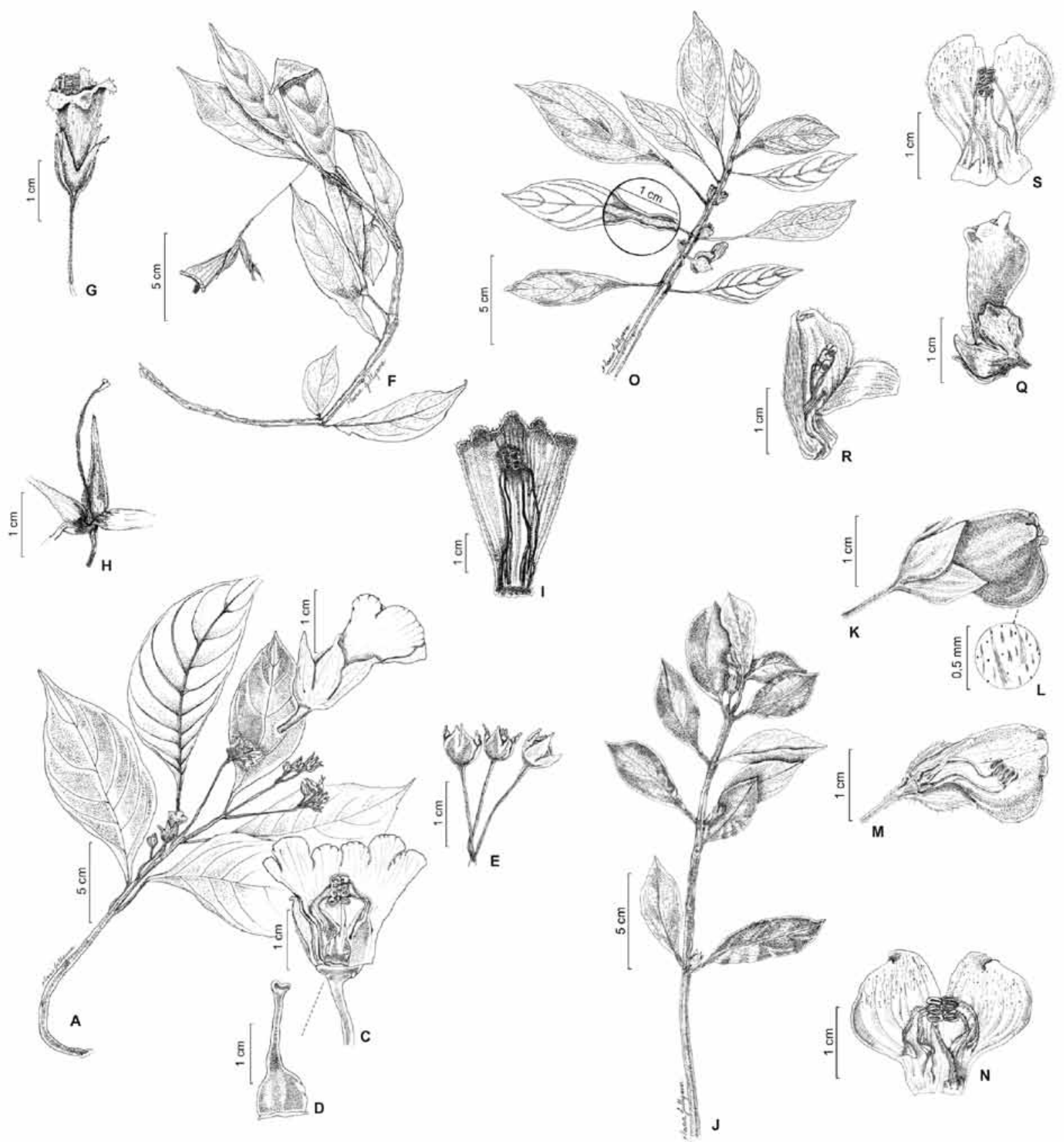

Figura 2. A-E. Besleria umbrosa. A. Hábito (Martinelli 7712); B. Flor; C. Secção longitudinal da flor evidenciando o gineceu e o androceu; D. Gineceu em detalhe; E. Ramo de frutos imaturos com cálices persistentes (B-E: Neto \& Silva 307). F-I. Nematanthus crassifolius. Hábito (F: Canela 8, RB); G. Flor; H. Flor sem corola evindenciando o gineceu; I. Corola e estames (G-I: Martinelli 10747). J-N. Nematanthus fornix. J. Hábito; K. Corola gibo-ventricosa; L. Detalhe dos tricomas e glândulas; M. Secção longitudinal da flor evidenciando o gineceu e o androceu; N. Corola, gineceu e androceu (J-N Canela 19). O-S. Nematanthus lanceolatus O. Hábito; P. Detalhe da base da folha atenuada; Q. Corola ventricoso-entumescida; R. Secção longitudinal da corola evidenciando o androceu - vista lateral; S. Secção longitudinal da corola evidenciando o androceu - vista frontal (O-S: Barros 2).

Figure 2. A-E. Besleria umbrosa. A. Habit (Martinelli 7712); B. Flower; C. Longitudinal section of the flower showing gynoecium and androecium; D. Gynoecium; E. Branch with young fruits showing the persistent calyx (B-E: Neto \& Silva 307). F-I. Nematanthus crassifolius. F. Habit (F: Canela 8, RB); G. Flower; H. Flower without corolla showing gynoecium; I. Corolla and stamens (G - I: Martinelli 10747). J-N. Nematanthus fornix. J. Habit; K. Gibo-ventricose corolla; L. Hairs and glandules; M. Longitudinal section of the flower in showing the gynoecium and androecium; N. Corolla, gynoecium and androecium (Canela 19). O-S. Nematanthus lanceolatus. O. Habit; P. atenuate leaf base; Q. Bloated-ventricose corolla ; R. Longitudinal section of the corolla showing the androecium - side view; S. Longitudinal section of the corolla showing the androecium - front view (Barros 2). 
limites do planalto (tabela 1). Coletada com flores de setembro a novembro.

Nematanthus lanceolatus (Poir.) Chautems, Diss. Bot. 112: 189. 1988.

Figura 2O-S

Subarbustos terrestres ou epifíticos, ramo cilíndrico, glabrescente. Folhas às vezes anisófilas, pecíolo 1,3 - 6,4 cm, vinoso, pubescente; lâmina oblanceolado-lanceolada, 7-17,5 × 1,9-2,8 cm, ápice acuminado, base atenuada, pubescente em ambas as faces, margem glabra. Flores geralmente 1-2 por axila, ressupinadas; pedicelo 4-8 $\mathrm{mm}$, pubescente; brácteas ausentes; sépalas $0,5-1 \mathrm{~cm}$ orbiculares, oval-arredondadas, pubérulas, vermelhas; margem ondulada a denticulada; corola 2,3-2,5 $\times 0,6 \mathrm{~cm}$, ventricoso-intumescida, laranja; lobos eretos e patentes, laranja com borda amarela, face interna glabra a pubescente e face externa pubescente ou tomentosa; filetes 0,9 3,4 cm, glabros; ovário pubescente; estilete ca. 0,6 $\mathrm{mm}$, glabro. Fruto ca. 1,0-1,2 × 1,4-1,5 cm.

Material selecionado: BRASIL. RIO DE JANEIRo: Itatiaia, Caminho do Lago Azul, 7-X-1945, fl., Altamiro et al. 39 (RB); Parque Nacional do Itatiaia, Trilha para a Cachoeira do Itaporani, 22VIII-2004, fl., Barros et al. 2 (RB); 15-X-2003, fl., Canela et al. 27 (RB); trilha do Hotel Simon para os Três Picos, 9-XI-1993, fl., Sylvestre et al. 919 (RB); Visconde de Mauá, Cruz, antiga Fazenda da Cruz, margem do rio Cruz, 6-X-1994, fl., Braga et al. 1404 (RB); margem do Rio Campo Belo, 10-X-1977, fl., Martinelli 3199 (RB). Ocorre no sul da Bahia, Minas Gerais, Espírito
Santo e Rio de Janeiro (Chautems 1988). Na Cadeia do Espinhaço, ocorre nas regiões do planalto de Diamantina, da Serra do Cipó e do Sul (Araújo et al. 2005). Na área de estudo, ocorre a ca. 850-900 $\mathrm{m}$, em locais úmidos, ocorrendo na montanha inferior segundo Segadas- Vianna (1965), sendo área ocupada por mata úmida (tabela 1). Coletada com flores de agosto a novembro. Assemelha-se muito a Nematanthus hirtellus espécie que ocorre na Serra dos Órgãos, mas ausente da Serra da Mantiqueira, diferenciando-se desta pela base de suas folhas que é atenuada, enquanto que $N$. hirtellus apresenta a base cuneada, tamanho do pecíolo (1,3-6,4 cm em $N$. lanceolatus e 4,5-7 $\mathrm{cm} N$. hirtellus) e do cálice (sépalas 0,5-1 vs. ca. $1,5 \mathrm{~cm}$ ) e cor do lobo da corola (laranja com borda amarela vs. totalmente amarela, vermelho-alaranjado ou rosa intenso).

Sinningia Nees. Ann. Sci. Nat. (Paris), Ser. I. 6: 296. 1825.

Ervas tuberosas, litofíticas ou terrestres, anual, ou, às vezes perenes, ramos cilíndricos. Folhas opostas, às vezes verticiladas, membranáceas, pecíolo verde a verde-escuro, margem crenada, serreada ou denteada. Inflorescência axilar ou terminal, cimosa, pseudo-racemosa ou espiciforme, com brácteas. Flores vistosas; sépala verde a vermelho escuro; corola tubulosa, 5-lobada, simetria bilobada, vermelho esmaecido a vermelhovivo; anteras exsertas a inclusas; nectário formado de 5 glândulas ou reduzido a 1-2 dorsais; ovário súpero a semi-ínfero, estigma incluso. Fruto cápsula loculicida.

Chave para a identificação das espécies de Sinningia ocorrentes no PNI

1. Folhas com pecíolo 13,5-18,5 cm compr.; inflorescência glabra.

S. gigantifolia

1. Folhas com pecíolo 0,1-3,4 cm compr. ou folhas sésseis; inflorescência pubescente

2. Inflorescência espiciforme S. allagophylla

2. Inflorescência em cimeira

3. Lâmina foliar cordiforme S. magnifica

3. Lâmina foliar lanceolada, elíptica, oval ou oval-elíptica

4. Corola 0,8-2,5 $\times 0,4-2 \mathrm{~cm}$, tubulosa; estilete menor que $3 \mathrm{~cm}$ compr. S. aggregata

4. Corola 3-4 × 0,5-0,9 cm, cilíndrica com base gibosa, ligeramente constricta próximo à base; estilete maior que $4,5 \mathrm{~cm}$ compr.

S. sceptrum

3.1 Sinningia aggregata (Ker Gawl.) Wiehler, Selbyana 1: 32. 1975.

Figura 3A-B

Ervasasubarbustos, cauleaéreoanual, glandulosopubescente. Folhas opostas ou 3-verticiladas, levemente anisófilas; pecíolo $0,4-1 \mathrm{~cm}$; lâmina oval ou oval-elíptica, 5,2-2,2 × 6,5-2,3 cm, ápice e base subagudos, margem crenada, esparsa a densamente pubescente, glanduloso- pubescente em ambas as faces. Inflorescência em cimeira, pubescente, 1-8 
flores, axilares, sésseis; flores subsésseis ou pedicelo com até $0,2 \mathrm{~cm}$; pedúnculo $1,7-3 \mathrm{~cm}$; bráctea $0,5-$ $0,7 \mathrm{~cm}$; sépalas ca. $1,3-0,5 \times 1-0,5 \mathrm{~cm}$, ovadolanceoladas, pubescentes, verdes; corola 0,8-2,5 $\times$ 0,4-2 cm, tubulosa, vermelho-clara; ligeramente constrita na base e depois progressivamente alargada, lobos patentes, subiguais, vermelhos ou alaranjados, face interna e externa glabrescente a esparsamente pubescente; filete 2,5-2,8 cm, anteras unidas em retângulo, pubescentes, ligeiramente exertos; ovário glabrescente, estilete incluso a pouco exserto, $2,1 \mathrm{~cm}$, glabrescente. Fruto ca. 1-2 cm.

Material selecionado: BRASIL. RIO DE JANEIRO: Itatiaia, Serra do Itatiaia, Mont Serrat, 23-X-1903, fl., Dusén 2177 (S).

Material adicional: BRASIL. MINAS GERAIS, Buenópolis, Serra do Cabral, 13-X-1988, fr., Harley 24923 (RB); Diamantina, 16-XII-2004, fl., Forzza 3747 (RB); Goiás, Posse, 4-XII-2003, fl., Mello-Silva 2292 (RB); Guarani de Goiás, 5-XII-2003, fl., Forzza 2574 (RB).

Distribui-se pelo Brasil em Tocantins, Goiás, Mato Grosso do Sul e Rio de Janeiro a Santa Catarina. Foi encontrada também nas regiões de planalto da Diamantina e Sul, sendo encontrada entre rochas no campo rupestre (Araújo et al. 2005). Na área de estudo ocorre no Mont Serrat, onde estima-se que o indivíduo tenha sido coletado entre as altitudes de 800 a $1.700 \mathrm{~m}$. Isto abrange as faixas altitudinais que Segadas-Vianna (1965) denominou de montanha inferior e superior, sendo áreas cobertas por matas (tabela 1). Coletada com flores praticamente outubro e frutos em janeiro e fevereiro.

\subsection{Sinningia allagophylla (Mart.) Wiehler, Selbyana 1(1): 32. 1975. \\ Figura 3A-E}

Ervas hemicriptófitas, caule aéreo anual, viloso. Folhas opostas, às vezes 3-verticiladas; pecíolo 1-3 $\mathrm{mm}$, verde, tomentoso; lâmina elíptica a oblonga, 6-6,7 $\times 2-2,5 \mathrm{~cm}$, ápice obtuso a agudo, base atenuada, margem crenada, face abaxial pubescente ao longo da nervura; face adaxial pubescente; margem pubescente. Inflorescência espiciforme, pubescente, $10,5-20 \mathrm{~cm}$, terminal; flores subsésseis, pubescente; pedicelo inconspícuo ou até $1,2 \mathrm{~cm}$; brácteas mais curtas que as flores, ca. 1,2 $\times 0,2 \mathrm{~cm}$, lanceoladas, face adaxial e abaxial tomentosas, margem tormentosa; sépalas ca. $1 \times 0,6 \mathrm{~cm}$, foliáceas, agudas, pubescentes, verdeavermelhadas; corola 1-1,6 $\times 0,5 \mathrm{~cm}$, urceoladotubulosa, não bilabiada, vermelho-alaranjada; lobos patentes, subiguais, vermelho-alaranjado, face interna e externa pubescente; filetes de 1-1,2 cm, anteras unidas em retângulo, pubescentes; ovário glabrescente, estilete $8 \mathrm{~mm}$, glabrescente. Fruto ca. $1,2 \times 1,5 \mathrm{~cm}$.

Material selecionado: BRASIL. RIO DE JANEIRO: Itatiaia, Planalto, 7-I-1947, fl., Duarte et al. 831 (RB); Entre km 18 e 17, 13-I-1961, fl., Flaster 120 (R); Entre Rebouças e Massenas, 14-I-1961, fl., Flaster 109 (R); Serra do Itatiaia, in montosis, II1894, fl., fr., Ule 207 (R).

Material adicional: BRASIL. PARANÁ: Curitiba, Capão do centro Politécnico, 9-XI-1993, fl., Ribas et al. 607 (RB).

Ocorre em áreas abertas ou campos no Paraguai, Uruguai e Argentina. No Brasil, nas regiões CentroOeste, Sul e Sudeste, tanto nos campos do cerrado como nos campos de altitude ou campos sulinos (Chautems \& Kyiama 2003). Na área de estudo é encontrada entre 2.000 e $2.300 \mathrm{~m}$, no que SegadasVianna (1965) considera planalto, uma área dominada pelos campos de altitude (tabela 1). Coletada com flores em janeiro.

3.3 Sinningia gigantifolia Chautems, Candollea 45: 384. 1990.

Figura 3F-J

Ervas litofíticas, caule cilíndrico, muitas vezes perene na base, glabro a pubescente. Folhas opostas, pecíolo 13,5-18,5 cm, verde, glabrescente; lâmina cordada a ovada, 17,2-24, $5 \times 4,9-17,1$ $\mathrm{cm}$, ápice de acuminado a obtuso e base cordada, margem irregularmente denteada, face abaxial pubescente, face adaxial pubérula, margem ciliada. Inflorescência paniculada, glabra, 33-36,5 cm, com aproximadamente 7-12 flores por ramo; pedicelo ca. $1,7 \mathrm{~cm}$, glabro; brácteas ca. $6 \mathrm{~mm}$, lanceolada a elíptica, em ambas as faces; sépalas ca. $5 \times 4 \mathrm{~mm}$, foliáceas, acuminado-arredondadas, glabras, verdeescura; corola 3-2,7 $\times 0,6 \mathrm{~cm}$, tubulosa, vermelhovivo, lobos ovados-lanceolados, concolores, face interna e externa glabra; filetes ca. 2,1-2,5 cm, glabros, anteras unidas em retângulo; ovário glabro, estilete ca. $2 \mathrm{~cm}$, glabro; nectário com glândula dorsal bilobada. Fruto $1,5 \times 1,3 \mathrm{~cm}$.

Material selecionado: BRASIL. Rio DE JANEIRO: Itatiaia, Caminho Rebouças, Prateleiras, 2.350 m, 13III-1960, fl., Martins 165, (GUA, R); Caminho para o Parque, 18-XI-1992, fl. fr., Alves et al. 660 (GUA); Km 15, mais ou menos 15, 13-I-1961, fl., Flaster 121 (R); Estrada subindo ao refúgio das Agulhas Negras 
cerca $7 \mathrm{~km}$ da estrada alta, 16-II-1989, fl., Chautems et al. 324 (R); Serra do Itatiaia, in campo, III-1894, fl., Ule 206, (R); 1-X-1997, fl., Silva Neto et al. 1185 (RB); Maromba, Trilha para Cachoeira Itaporani, 25XI-1994, fl., Braga et al. 1675 (RB).

Ocorre na área estudada tanto entre 2.100 e 2.400 $\mathrm{m}$, em locais mais secos e frios, quanto a $850-900 \mathrm{~m}$, em locais úmidos, sobre pedras. Ocorre na Serra da Mantiqueira, desde a divisa de São Paulo até o sul de Minas Gerais, além da Serra do Brigadeiro e Parque Nacional do Caparaó, na divisa com o Espírito Santo. Esta espécie foi recentemente registrada para o estado de São Paulo por Arzolla et al. (2007). Este novo registro é, segundo os autores, um elo entre a região de Itatiaia, no estado do Rio de Janeiro, e os municípios de Extrema e o distrito de Monte Verde, no município de Camanducaia, na divisa entre os estados de Minas Gerais e São Paulo, onde essa espécie já havia sido coletada. No Parque está representada nas diferentes formações, ocorrendo desde a montanha inferior até o planalto representado pelos campos de altitude, até a montanha inferior (Segadas-Vianna 1965) (tabela 1). Coletadas com flores de outubro a janeiro.

Sinningia magnifica (Otto \& A. Dietr.) Wiehler, Selbyana 1(1): 32. 1975.

Figura 3K-Q

Erva rupícola; caule herbáceo, ereto, viloso e glândulas presentes. Folhas opostas, as vezes anisófilas, pecíolo $0,8-3,4 \mathrm{~cm}$, verde, viloso, lâmina foliar cordiforme, 3,7-11,5 × 4,5-9 cm, ápice acuminado, base de cordada, margem crenada a denteada, face abaxial tomentosa, face adaxial velutina; margem crenulada a denticulada, vilosa. Inflorescência cimosa, pubescente, $12-30 \mathrm{~cm}, 2-12$ flores em cada ramo, pedicelo 2-3,4 cm, velutino, brácteas e bractéolas, 2 por ramo, 1,5-1,3 cm, aspecto foliáceo, parte superior e inferior vilosas; sépalas ca. $6 \times 4 \mathrm{~mm}$, rotáceas, pubescentes; corola 3,5-5 cm, tubulosa, bilabiada, vermelho-vivo; lobos triangulares a ovado-lanceolados, face interna glabra, parte externa pubescente a velutina, 2 lobos dorsais unidos, eretos; filetes ca. 3,6-3,9 cm, glabrescente, anteras unidas em disco; ovário pubescente, estilete $4 \mathrm{~cm}$, pubescente. Fruto ca. $1,6 \times 1,5 \mathrm{~cm}$.

Material selecionado: BRASIL. RIO DE JANEIRO: Itatiaia, Entrada do Maromba, III-1948, fl., Duarte 1198 (RB); Parque Nacional do Itatiaia. Engenheiro Passos, trilha para o abrigo Rebouças, 18-III-2006, fl., Mansano et al. 297 (RB); Trilha Itaporani, 19-III2006, fl., Mansano et al. 301 (RB); Minas GeraIs:
Engenheiro Passos, Estrada Itatiaia - Engenheiro Passos 18-III-2006, fl., Mansano et al. 283 (RB); Serra do Itatiaia, rochedos, IV-1894, fl., Ule 274 (R). Material adicional: BRASIL. RIo DE JANEIRO, Nova Friburgo, Distrito de Macaé de Cima; Estrada para o sítio Sophronites, 15-XI-1993, fl., Alves 4375 (RB); Resende, Serra de Itatiaia, Visconde de Mauá, 1-IV1979, fl., Martinelli 5714 (RB).

Ocorre nas Serras de Minas Gerais, Espírito Santo, Rio de Janeiro e São Paulo (Chautems \& Kiyama 2003). Na área estudada são encontradas desde 1.000 até $2.100 \mathrm{~m}$, em locais úmidos, próximo a cachoeiras. Espécie representada nas diferentes formações do Parque, ocorrendo desde as matas densas da montanha inferior (Segadas-Vianna 1965) até os campos do planalto (tabela 1). Coletada com flores de fevereiro a julho.

Sinningia sceptrum (Mart.) Wiehler, Selbyana 1: 32. 1975.

Figura 3J)

Ervas ou subarbustos, glabro a glabrescente. Folhas opostas ou 3-4 verticilada, não peltadas; pecíolo $0,1-0,3 \mathrm{~cm}$, inserido próximo à base da lâmina ou ausente, verde; lâmina lanceolada a elíptica, 4,8-0,8 × 7,0-2,7 cm, ápice acuminado, base aguda ou obtusa, margem denteada ou serreada, face adaxial pubescente, face abaxial verde a marrom, densamente pubescente. Inflorescência cimosa, pubescente, 7- 5 flores na axila de bráctea verticilada, séssil; pedicelo $2-3,4 \mathrm{~cm}$; sépalas $0,5-1$ $\times 0,4-0,7 \mathrm{~cm}$, lanceoladas a ovada, faces abaxial e adaxial pubescentes a tomentosas, verdes; corola 3-4 $\times 0,5-0,9 \mathrm{~cm}$, cilíndrica com base gibosa, ligeramente constricta próximo a base, laranja-avermelhada, pálida, face externa pubescente, face interna glabra; filete 3-3,5 cm, estaminódio presente, anteras unidas em retângulo; ovário pubescente, estilete incluso, às vezes exserto, 5-5,5 cm, pubescente. Fruto 0,9-2 $\times$ $1-2 \mathrm{~cm}$.

Material examinado: BRASIL. Rio DE JANEIRO: Serra do Itatiaia, s.d., fl., Dusén s.n. (S).

Material adicional: BRASIL. RIO DE JANEIRO: Nova Friburgo, Macaé de Cima, 4-XII-1993, fl., Vieira 453 (RB); 1-III-1969, fr., Braga 1529 (RB). EspíRITO SANTO, São Mateus, 15-X-1992, fl. fr., Hatschbach 58089 (RB). Minas Gerais, Viçosa, 23-XII-1937, fr., Kuhlmann 2677 (RB).

Ocorre da Bahia até o Rio de Janeiro (Chautems 1990). É encontrada na Cadeia do Espinhaço em Minas Gerais, numa faixa altitudinal de 800-1.200 m, 


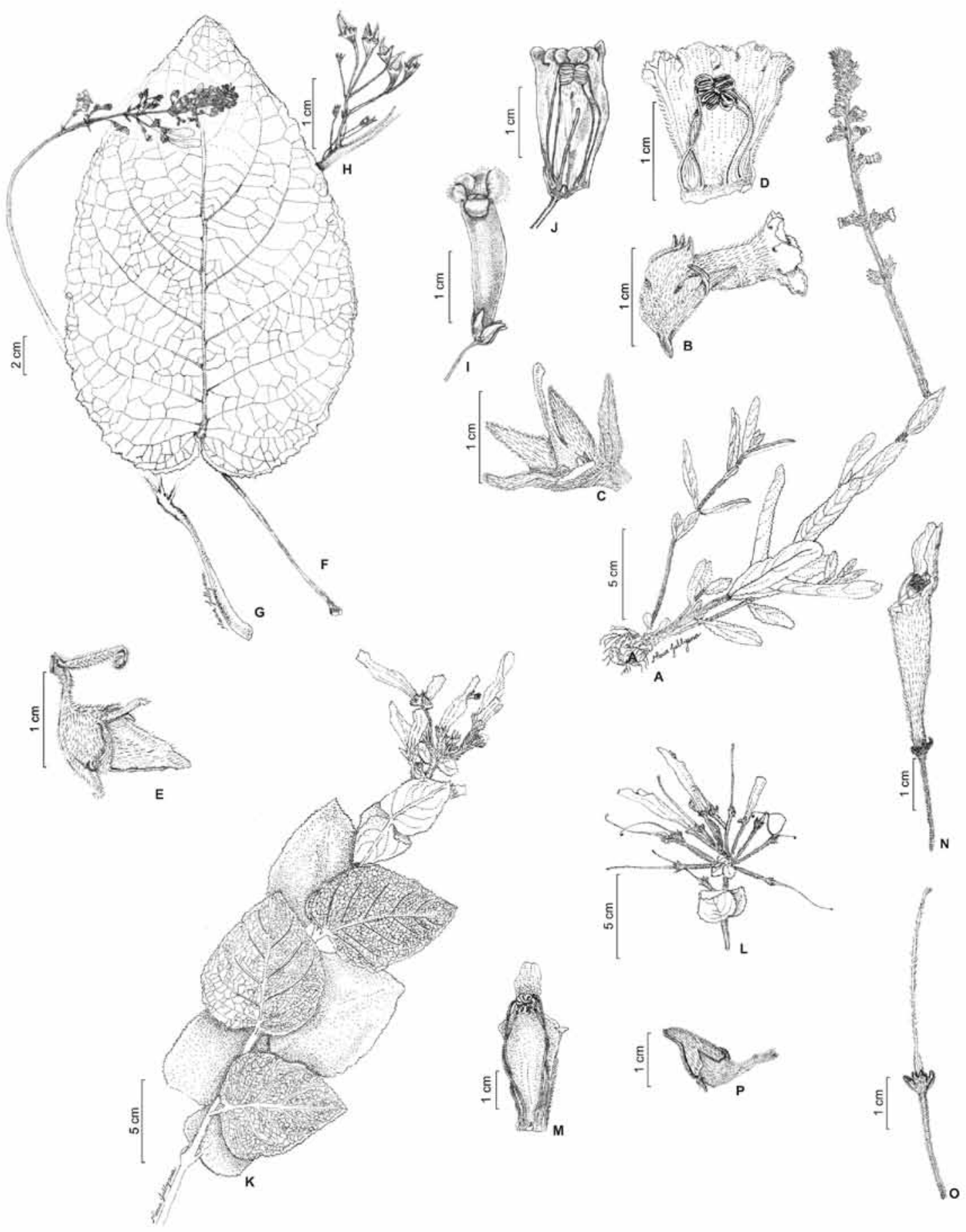

Figura 3. A-E. Sinningia allagophylla. A. Hábito; B. Flor em vista lateral evidenciando a corola campanulada; C. Flor com a corola removida evidenciando o gineceu; D. Secção longitudinal da corola evidenciando o androceu; E. Fruto. (A-E Ribas 607). F-J. Sinningia gigantifolia. F. Folha; G. Detalhe do ramo com inflorescência; H. Ramo com frutos; I. Flor; J. Secção longitudinal da flor evidenciando o gineceu e o androceu. (F-G e I-J: Canela 36; H: A.P.D. 801). K-Q. Sinningia magnifica. K. Hábito; L. Detalhe ramo da inflorescência; M. Secção longitudinal da corola evidenciando os estames; N. Flor evidenciando a corola tubular com estames exsertos; O. Flor com remoção da corola e androceu evidenciando o gineceu; P. Fruto. (H, J-L: Alves 4375; I: Forzza 3419; M: Martinelli 4722).

Figure 3. A-E. Sinningia allagophylla. A. Habit; B. Campanulate corolla in lateral view; C. . Flower without the corolla showing the gynoecium; D. Longitudinal section of the corolla showing the androecium; E. Fruit. (A-E Ribas 607). F-J. Sinningia gigantifolia. F. Leaf; G. Branch with inflorescence; H. Branch with fruits; I. Flower; J. Longitudinal section of the flower showing the gynoecium and androecium. (F-G e I-J: Canela 36; H: A.P.D. 801). K-Q. Sinningia magnifica K. Habit; L. Branch with inflorescence; M. Longitudinal section of the corolla showing the stamens; N. Flower showing the tubular corolla with exserted stamens; O. Gynoecium; P. Fruit. (H, J-L: Alves 4375; I: Forzza 3419; M: Martinelli 4722). 
em locais geralmente na borda da mata, às vezes em terreno alagável. Coletada com flores de fevereiro a abril e com frutos em abril. Na área de estudo foi encontrada na Serra de Itatiaia numa faixa altitudinal determinada por Segadas-Vianna (1965) de montanha inferior (tabela 1).

Dentre os levantamentos feitos para Gesneriaceae em áreas do Sudeste brasileiro, a cadeia do Espinhaço é a que sem dúvida apresenta maior diversidade com seis gêneros e 21 espécies. O PNI com seus três gêneros e nove espécies apresenta a sétima maior diversidade de espécies (tabela 2).

Dentre as espécies apresentadas por Araújo et al. (2005), também ocorrem no PNI Nematanthus crassifolius, $N$. lanceolatus, Sinningia allagophylla, S. magnifica, S. aggregata e S. sceptrum (tabela 3). Outros trabalhos de Gesneriaceae foram feitos para determinadas áreas de Minas Gerais, sendo eles o de Leoni \& Chautems (2004) para o Parque Nacional do Caparaó e também o de Leoni et al. (2005) para o Parque Estadual da Serra do Brigadeiro. Dentre as espécies verificadas por Leoni \& Chautems (2004) para o Caparaó, há cinco em comum com o PNI, sendo elas Nematanthus crassifolius, $N$. lanceolatus, Sinningia allagophylla, S. gigantifolia e $S$. magnifica (tabela 3). Porém há gêneros como Paliavana e Vanhouttea que ocorrem no Caparaó e não foram encontradas no PNI. Leoni et al. (2005), estudando as Gesneriaceae do Parque Estadual da Serra do Brigadeiro, encontraram 12 espécies, sendo quatro em comum com o PNI, sendo elas Nematanthus crassifolius, N. lanceolatus, Sinningia gigantifolia e S. magnifica. Codonanthe e Vanhouttea, que não foram encontrados no Itatiaia (tabela 3), ocorrem no Brigadeiro. Vale a pena ressaltar que Besleria, foi encontrado no PNI, porém não observada na Cadeia do Espinhaço por Araújo et al. (2005), nem para o Caparaó no estudo de Leoni \& Chautems (2004) e nem para o Brigadeiro por Leoni et al. (2005).

A listagem das espécies de Gesneriaceae apresentadas por Lima \& Guedes-Bruni (1997), em seus estudos para a Reserva de Macaé de Cima, situada nas encostas da Serra do Mar do Rio de Janeiro, mostram que apenas Nematanthus crassifolius e $N$. lanceolatus (tabela 3) também são encontradas no PNI. Já Chautems (dados não publicados) cita para Macaé de Cima além do Nematanthus crassifolius, outras espécies em comum com o PNI, como Nematanthus fornix, Sinningia sceptrum, S. magnifica, porém não cita Nematanthus lanceolatus.

Outro estudo realizado para a APA-Cairuçu, localizada na Serra do Mar, por Konno (1997), lista 11 espécies de Gesneriaceae, sendo que apenas Nematanthus fornix é encontrada também no PNI. A APA-Cairuçu possui relevo com altitudes de 800 a $1.800 \mathrm{~m}$, sendo uma área com altitudes máximas muito inferiores ao PNI tornando-a uma área distinta em relação às Gesneriaceae.

Na Reserva Florestal da FEEMA, denominada Reserva Florestal Vista Chinesa, e seus arredores, Lima (1986), encontrou quatro espécies de Gesneriaceae, sendo que nenhuma ocorre no PNI.

Tabela 2. Quantificação por espécies e gêneros, nas áreas relacionadas (região Sudeste) ao Parque Nacional do Itatiaia.

Table 2. Number of species and genera in the Parque Nacional do Itatiaia and other areas from Southeastern Brazil.

\begin{tabular}{lccc}
\hline \multicolumn{1}{c}{ Localidade } & Número de gêneros & Número de espécies & Fonte \\
\hline Espinhaço & 6 & 21 & Araújo et al. (2005) \\
Rio das Pedras & 6 & 17 & Lopes et al. (2005) \\
Brigadeiro & 5 & 14 & Leoni et al. (2005) \\
Caparaó & 6 & 13 & Leoni \& Chautems (2004) \\
APA Cairuçu & 5 & 12 & Konno (1997) \\
Macaé de Cima & 5 & 11 & Lima \& Guedes-Bruni (1997) \\
Itatiaia & 3 & 9 & Presente estudo/ this study \\
FEEMA & 4 & 4 & Lima (1986) \\
\hline
\end{tabular}


Tabela 3. Comparação das Gesneriaceae ocorrentes no Parque Nacional do Itatiaia com as de outras áreas distintas de Minas Gerais e Rio de Janeiro; X significa a presença da espécie na área indicada na respectiva coluna. Os números sobrescritos ligam a área à obra de referência usada. Fonte: 1Araújo et al. (2005), 2Leoni \& Chautems (2004), 3Leoni et al. (2005), 4aLima \& Guedes-Bruni (1997) \& 4b Chautems (lista atualizada de Macaé de Cima, dados não publicados), 5Konno (1997), e 6Lopes et al. 2005.

Table 3. Comparation of the Gesneriaceae occuring in the Parque Nacional do Itatiaia with other areas in Minas Gerais and Rio Janeiro. 1Araújo et al. (2005), 2Leoni \& Chautems (2004), 3Leoni et al. (2005), 4aLima \& Guedes-Bruni (1997) \& 4b Chautems (updated checklist of Macaé de Cima, unpublished), 5Konno (1997), e 6Lopes et al. 2005.

\begin{tabular}{lccccccc}
\hline & Espinhaço $^{1}$ & Caparaó $^{2}$ & Brigadeiro $^{3}$ & $\begin{array}{c}\text { Macaé de } \\
\text { Cima }^{4 a}\end{array}$ & $\begin{array}{c}\text { Macaé de } \\
\text { Cima }^{4 b}\end{array}$ & $\begin{array}{c}\text { APA- } \\
\text { Cairuçu }\end{array}$ & $\begin{array}{c}\text { Rio das } \\
\text { Pedras }^{6}\end{array}$ \\
\hline $\begin{array}{l}\text { Besleria umbrosa } \\
\begin{array}{l}\text { Nematanthus } \\
\text { crassifolius }\end{array}\end{array}$ & $\mathrm{X}$ & $\mathrm{X}$ & $\mathrm{X}$ & $\mathrm{X}$ & $\mathrm{X}$ & & $\mathrm{X}$ \\
$\begin{array}{l}\text { N. fornix } \\
\text { N. lanceolatus }\end{array}$ & $\mathrm{X}$ & $\mathrm{X}$ & $\mathrm{X}$ & $\mathrm{X}$ & & \\
$\begin{array}{l}\text { Sinningia aggregata } \\
\text { S. allagophylla }\end{array}$ & $\mathrm{X}$ & $\mathrm{X}$ & $\mathrm{X}$ & & & & \\
$\begin{array}{l}\text { S. gigantifolia } \\
\text { S. magnifica }\end{array}$ & $\mathrm{X}$ & $\mathrm{X}$ & $\mathrm{X}$ & & & \\
S. sceptrum & $\mathrm{X}$ & $\mathrm{X}$ & $\mathrm{X}$ & & $\mathrm{X}$ & \\
\hline
\end{tabular}

Já Lopes et al. (2005), em seu estudo sobre a diversidade florística das Gesneriaceae na Reserva Rio das Pedras em Mangaratiba, também no estado do Rio de Janeiro, encontraram 17 espécies para esta família sendo que apenas Nematanthus crassifolius também ocorre no PNI.

Nota-se claramente que, pelo menos para Gesneriaceae, a flora de Itatiaia é muito mais parecida com as áreas de Minas Gerais como a da Serra do Caparaó, do Brigadeiro e a Cadeia do Espinhaço (figura 4) do que com as áreas do Rio de Janeiro estudadas. Estas formações apresentam altitudes mais elevadas que a Serra do Mar, propiciando assim o estabelecimento de floras parecidas. A Cadeia do Espinhaço tem como limite sul o município de Ouro Branco, Minas Gerais e ao norte o município de Juazeiro, Bahia (Derby 1906, Harley 1995). Nesta região também se notam formações com altitudes relativamente elevadas sendo encontradas serras com médias de até $2000 \mathrm{~ms} . \mathrm{m}$, sendo os campos rupestres e as matas de neblina ocupando as altitudes mais elevadas (Araújo et al. 2005). Justamente por apresentar gradientes altitudinais semelhantes e por estarem relativamente próximas também é plausível se esperar que as Gesneriaceae da Serra da Mantiqueira e da Cadeia do Espinhaço apresentem similaridades. A Reserva Ecológica de Macaé de Cima, uma área com alto relevo se mostrou mais similar a Itatiaia, Caparaó, Brigadeiro e Espinhaço do que com as áreas de relevo mais baixo do Rio de Janeiro como a APA de Caiuruçu e Rio das Pedras (figura 4).

Por outro lado, a pouca semelhança entre Itatiaia e as demais floras de áreas do Rio de Janeiro (Lima \& Guedes-Bruni 1997, Konno 1997, Lima 1986, Lopes et al. 2005), com exceção da APA de Caiuruçu e Rio das Pedras (figura 4), sugerem que os ambientes oferecidos pelos tipos de formações apresentam maior influência na vegetação do que a proximidade geográfica.

Não foi verificado nenhum endemismo de Gesneriaceae para o PNI, observado para muitas famílias na área (Brade 1956), um dos fatores para tanto pode ser devido à faixa altitudinal ao qual Gesneriaceae são encontradas, não sendo muito características dos cumes, regiões onde se concentram grande número de espécies endêmicas do PNI. A única espécie de Besleria é encontrada apenas na base da montanha do PNI em altitudes de até $680 \mathrm{~m}$. Nematanthus é um gênero encontrado principalmente em faixas altitudinais mais baixas do Parque, com apenas $N$. fornix atingindo os limites dos 


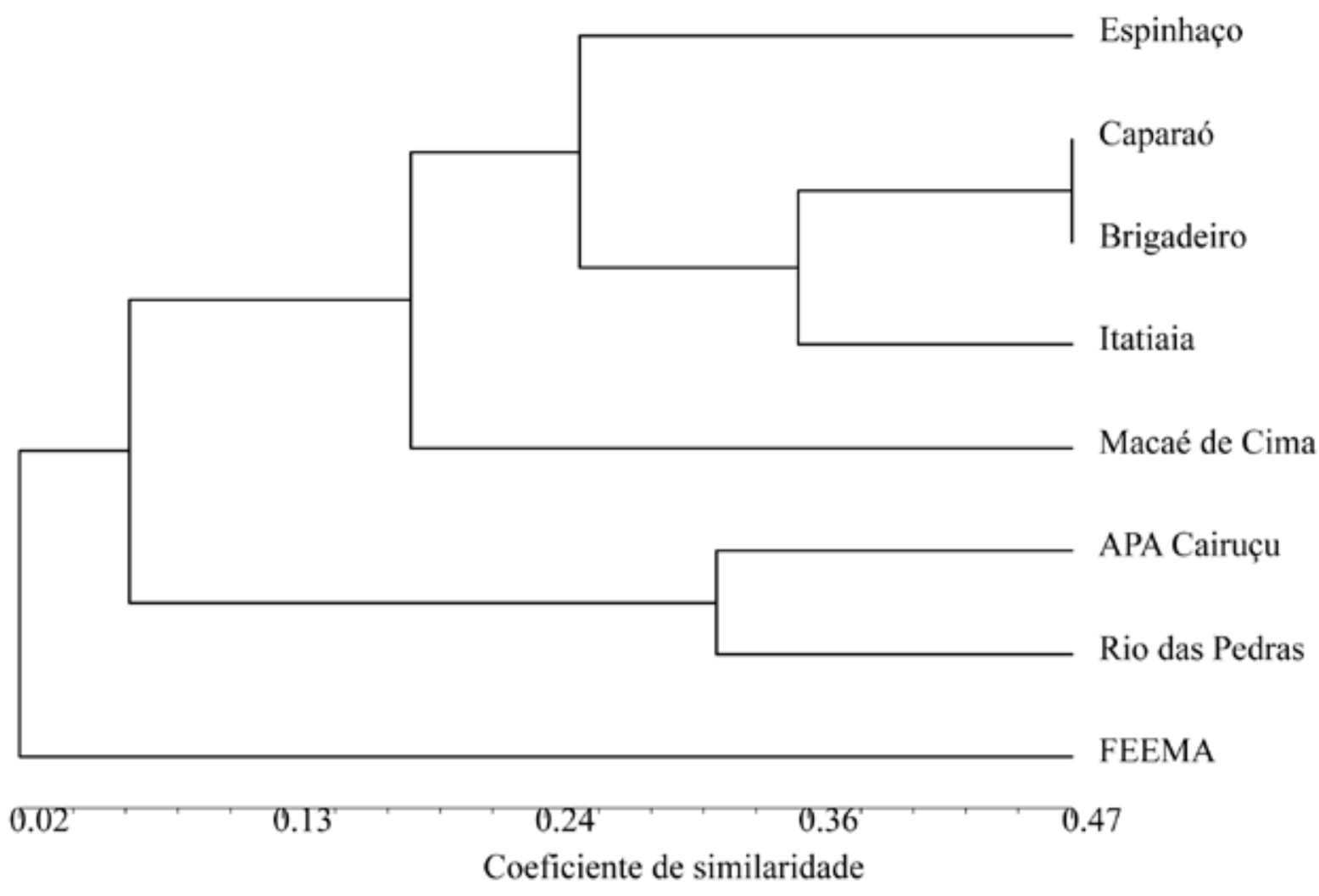

Figura 4. Dendrograma obtido da análise de similaridade entre Itatiaia, Cadeia do Espinhaço, Serra do Caparaó, Serra do Brigadeiro, Macaé de Cima, FEEMA, Cairuçu e Rio das Pedras, através de UPGMA.

Figure 4. UPGMA dendrogram obtained from the similarity analysis between Itatiaia, Cadeia do Espinhaço, Serra do Caparaó, Serra do Brigadeiro, Macaé de Cima, FEEMA, Cairuçu e Rio das Pedras.

campos de altitude do planalto. Por outro lado, quase todas as espécies de Sinningia (com exceção de $S$. aggregata e $S$. sceptrum) aqui estudadas ocorrem nos campos de altitude, sendo que $S$. gigantifolia e $S$. magnifica também podem ser encontradas nas matas de faixa altitudinal mais baixa do Parque.

Besleria umbrosa e Nematanthus fornix estão entre as espécies que apresentam uma distribuição mais restrita, ocorrendo entre os estados de São Paulo e Rio de Janeiro nas formações da Serra do Mar e da Mantiqueira. Nematanthus crassifolius, $N$. lanceolatus e Sinningia magnifica são distribuídos pela região Sudeste do Brasil, principalmente nas Serras do Mar e da Mantiqueira.

Sinningia allagophylla é, dentre as espécies encontradas no Parque, a que apresenta a maior distribuição tendo sua abrangência atingindo o Paraguai, Uruguai e no Brasil, as regiões Sul, Sudeste e Centro-Oeste.

A citação de Codonanthe para o Parque por Brade (1956) é duvidosa pela ausência da citação do material examinado.

\section{Agradecimentos}

Este trabalho é parte da Iniciação Científica e monografia da primeira autora no Programa Mata Atlântica do Instituto de Pesquisas Jardim Botânico do Rio de Janeiro. Os autores agradecem ao CNPq pela concessão da bolsa de iniciação científica a primeira autora; à Petrobrás pelo financiamento de parte desse trabalho (convênio Petrobrás/ JBRJ: 610.4.025.02.3); aos curadores dos herbários mencionados pela facilitação de acesso ao acervo; a Viviane Mezabarba, Acácia Reiche, Pedro Habibe e Rosembergue Silva pelas várias ajudas no decorrer deste trabalho; as desenhistas Ana Lúcia de Souza e Claudia de Miranda pela ajuda na confecção das pranchas; ao Gustavo Heiden pela ajuda nas análises de comparações florísticas.

\section{Literatura citada}

Araújo, A.O., Souza, V.C. \& Chautems, A. 2005. Gesneriaceae da Cadeia do Espinhaço 
de Minas Gerais, Brasil. Revista Brasileira de Botânica 28: 109-135.

Arzolla, F.A.R.P.; Paula, G.C.R; Chautems, A.P. \& Shepherd, J.G. 2007. O primeiro registro de Sinningia gigantifolia chautems no estado de São Paulo. Biota Neotrop. [online] 7; 373-377.

Barroso, G.M. 1957. Gesneriaceae. Flora do Itatiaia I. Rodriguésia 32: 131-135.

Barroso, G.M., Peixoto, A.L., Costa, C.G., Ichaso, C.L.F., Guimarães, E.F. \& Lima, H.C. 1984. Sistemática de angiospermas do Brasil, v.2, Universidade Federal de Viçosa, Viçosa.

Brade, A.C. 1956. A flora do Parque Nacional do Itatiaia. Boletim Parque Nacional Itatiaia 5: 1-92.

Chautems, A. 1993. Gesneriaceae. In: R. Spichiger \& L. Ramella (eds.). Flora del Paraguay 22: 1-40.

Chautems, A. \& Kiyama, C.Y. 2003. Gesneriaceae. In: M.G.L. Wanderley, G.J. Shepherd, A.M. Giuletti \& T.S. Melhem (eds.). Flora Fanerogâmica do Estado de São Paulo, v. 3. FAPESP, Rima Editora, São Paulo, pp. 75-103.

Derby, D.A. 1906. The Serra do Espinhaço. Brazilian Journal of Geology 14: 374-401.

Dusén, P. 1909. Beiträge zur Flora des Itatiaia. Arkiv för Botanik utgivet av K. Svenska Vetenskapsakademien 9: 1-50.

Dusén, P. 1903. Sur La flore de la Serra do Itatiaya au Brésil. Archivos do Museu Nacional do Rio de Janeiro 13: 1-119.

Harley, R.M. 1995. Introdução. In: B.L. Stannard (ed.). Flora of the Pico das Almas: Chapada Diamantina, Bahia, Brasil. Royal Botanic Gardens, Kew, pp. 43-76.

Holmgren, P.K., Holmgren, N.H. \& Bernett, L.C. 1990. Index Herbariorum, Part I: The herbaria of the Word, New York Botanical Garden, New York.

Judd, W.S. Campbell, C.S., Kellog, E.A. \& Stevens, P.F. 2002. Plant Systematics: a phylogenetic approach. Sinauer Associates, Sunderland.

Konno, T.U.P. 1997. Gesneriaceae. In: M.C.M. Marques, A.S.F Vaz \& R. Marquete (eds.). Flórula da APA Cairuçu, Parati, RJ: espécies vasculares. Série Estudos e Contribuições 14: 197-211.
Leoni, L. \& Chautems, A. 2004. Flora Fanerógama do Parque Nacional do Caparaó: Gesneriaceae. Pabstia 15: 1- 11.

Leoni, L., Chautems, A. \& Rocha, M.J.R. 2005. Flora Fanerógama do Parque Estadual da Serra do Brigadeiro: Gesneriaceae. Pabstia 16: 1-12.

Lima, H.C. \& Guedes-Bruni, R.R. 1997. Diversidade de plantas vasculares na Reserva Ecológica de Macaé de Cima. In: H.C. Lima \& R.R. Guedes-Bruni (eds.). Serra de Macaé de Cima: diversidade florística e conservação em Mata Atlântica. Jardim Botânico do Rio de Janeiro, Rio de Janeiro, pp. 29-39.

Lima, D.F. 1986. Gesneriaceae da Reserva Florestal da FEEMA e arredores. Albertoa 1: 37-40.

Lopes, T.C.C., Chautems, A. \& Andreata, R.H.P. 2005. Diversidade florística das Gesneriaceae na Reserva Rio das Pedras, Mangaratiba, Rio de Janeiro, Brasil. Pesquisa, Botânica 56: 75-102.

MA-IBDF \& FBCN. 1982. Plano de manejo-Parque Nacional do Itatiaia. Ministério da Agricultura, Instituto Brasileiro de Desenvolvimento Florestal, Fundação Brasileira para a Conservação da Natureza, Brasília.

Morim, M.P. 2002. Leguminosae arbustivas e arbóreas do Parque Nacional do Itatiaia: abordagem florístico-taxonômica. Tese de doutorado, Universidade Federal do Rio de Janeiro, Rio de Janeiro.

Rolf, F.J. 2000. NTSYSpc - numerical taxonomy and multivariate analysis system 2.1. Applied Biostatisctics, New York.

Segadas-Viana, F. \& Dau, L. 1965. Ecology of Itatiaia range, southeastern Brasil. I Altidudinal zonation of the vegetation. Arquivos Museu Nacional do Rio de Janeiro 53: 31-53.

Souza, V.C. \& Lorenzi, H. 2005. Botânica Sistemática: Guia ilustrado para identificação das famílias de Angiospermas da flora brasileira, baseado em APGII. Instituto Plantarum, Nova Odessa.

Weber, A. 2004. Gesneriaceae. In: K. Kubitzki (ed.). The families and genera of vascular plants. v. 7. Dicotyledons, Lamiales (except Acanthaceae incl. Avicennieae). Springer, Berlin, pp. 63-158.

\section{Lista de exsicatas:}

Altamiro 39 (2.3); Alves, M.V: 660 (3.3), 4375 (3.4); Aparício 831 (3.2); Barros, M. J: 1 (2.2), 2 (2.3); Brade 18862 ( 2.1); Braga: 1345, 1368 (2.1); Canela, M.B.F.: 8 (2,1), 19 (2.2), 27 (2.3); Chautems, A. 102 (2.1), 324 (3.3); Dusen, P.: 534 (2.1), 2177 (3,1), s.n. (S) (3,5); Flaster, B.: 120, 109 (3.2), 121 (3.3); Giordano, L.C.: 443 (2.1); Góes, O. C.: s.n. (RB 102309) (1.1); Landrum, L.R.: 2115 (2.2); Lima.: 314 (2.1); Luiz L.: 80 (1.1); Mansano, V.F.: 04-266 (2.1), 04-268 (2.2), 04-276 (2.1), 283 (3.4), 06-297 (3.4), 06-301 (3.4), 06-349 (1.1); 
Martinelli, G.: 7712 (1.1), 6180, 5714 (3.4); Neto, S. J. S.: 1185 (3.3); Pineslhi, R.B.: 13 (1.1); Ribas, O.S.: 607 (3.2); Rossi, L.: SP s.n. 276811(1.1); Ule, E.: 206 (3.3). 